Brit. J. vener. Dis. (1965), 41, 217.

\title{
SOME EMOTIONAL PROBLEMS DEALT WITH IN THE SPECIAL CLINIC*
}

\author{
BY \\ M. S. BIRD \\ Medical Social Worker, Special Treatment Centre, St. Bartholomew's Hospital, London
}

The Special Treatment Centre at St. Bartholomew's Hospital is a rather small compact clinic separated from the main out-patients department by a partition. There is also a private side entrance. My office is a large private room with an attractive carpet and pictures and comfortable armchairs, and I do not wear a white coat. These all help in making the patient feel more relaxed. New male patients with syphilis or gonorrhoea are normally referred to me, and $I$ also see other men who are worried about contact slips for wives or girl-friends or have other problems. Most women patients are also referred to me on their first attendance.

As is apparent from earlier papers (see Stubbs, $p$. 214), clinics in different areas of London tend to cater for particular categories of patients. At St. Bartholomew's Hospital many of the male patients are professional or business men, with a proportion from the Fleet Street backgrounds of journalism and advertising. The majority are commuters who work in the City and in Holborn, and live within a fairly wide radius of London. Many of the women and girls who attend are secretaries or bank clerks, or work in Fleet Street, with a smattering of art and drama students. There are a few local patients who live in the King's Cross and Angel districts. Of the immigrant patients, quite a large proportion are students or skilled craftsmen with a small group of unskilled workers. The patients to be discussed in this paper are teenagers and young adults, and male and female homosexuals.

\section{Teenagers and Young Adults}

In dealing with this group one needs to create an atmosphere in which they feel free to discuss their problems and feelings; this is essential, though often difficult. Though many of the young people come

\footnotetext{
*Paper read at a meeting of the MSSVD on January 29, 1965.
}

from social backgrounds where one would have expected the parents to have given some sort of sex education, in surprisingly few homes is sex ever discussed. Often the sex education given at school has been mainly confined to biology classes with little or no reference to the emotional and ethical aspects of the subject. On the whole, more boys than girls attend for a check-up because of worry over "VD" although they deny having had sexual intercourse. As no doubt occurs in all the other clinics, there is an influx of worriers after newspaper articles or radio or television programmes.

Many of the girls are very worried and feel guilty, especially on their first attendance. Their greatest fears seem to be that they will be permanently damaged so that they will be sterile or produce deformed babies, or that their parents will find out about their attendance at the clinic. Sometimes mothers have already noticed that their daughters are worrying or the girls feel they want to tell their mothers. We have a routine letter known as the "Worried Mother's Letter" which briefly explains that the daughter has a minor infection, that this is not VD, and that after a 3-month period of observation she will be discharged. So far, fortunately, we have had requests for such a letter only from patients with non-gonococcal infection. On the occasions when this letter has been given to the mother it appears to encourage a more adult relationship between mother and daughter and a greater freedom to discuss problems together.

Although many of the girls say that they are constantly worried about becoming pregnant very few seem to use any form of contraceptive regularly. If a girl does become pregnant during her attendance she is helped with her future plans: sometimes arrangements are made for her through a Mother and Baby Home or the National Council for the Unmarried Mother and Child, but often I continue 217 
to see her regularly, helping her while she decides on her own future and that of the baby.

The young lads are usually more reticent about their feelings and fears so that it often takes longer to help them feel relaxed and free to talk. Suggesting that they smoke or appealing to their sense of humour often breaks the ice, and once it is broken they are often more straightforward and open. Their main anxieties are how they are going to explain the contact slips to their girl-friends and persuade them to go to a clinic, or (if they have had a casual contact), whether they could transmit any infection to their regular girl-friend, or whether the infection will affect their future children. On the whole, boys seem less worried about their parents finding out. Often, as these young people discuss their problems, they reassess their values and see more clearly the factors governing their general attitude to life-both in their personal relationships with parents and friends and in their work. There are some with particular problems who continue to come at regular intervals to see the medical social worker after discharge. Recently several have come back months later asking for help in particular problems, such as trouble with police or drug addiction.

\section{Male Homosexuals}

Certain factors seem particularly recurrent in this group, yet, at the same time, there are wide differences in background and in behaviour. It is essential to have an understanding of these factors if these patients are to be helped to learn to live with their problems.

\section{Variations found in Different Age Groups}

Teenagers and Young Adults.-Many of these homosexuals are very promiscuous. At this stage the more overt "homosexual" characteristics of appearance, voice, and mannerism are apparent. These young men haunt the "gay" clubs and public houses of the West End nightly and each weekend. The free and superficially friendly atmosphere draws the rather shy, introverted young man like a magnet. Recently I have heard of two lads who were offered $£ 25$ each for an hour's appointment with an anonymous older homosexual through the manager of a club. A large number admit having taken drugs of one sort or another at some stage. They have fluctuating moods, with or without drugs, from extreme exhilaration to suicidal "horrors", and often describe terrifying daytime fantasies and nightmares. Very few have come to terms with their homosexuality by this stage and are still battling with their emotional conflict about it.
25 to 35-year-olds.-Although aware of feeling "different" while living in the provinces many patients are struck by the full realization of their homosexuality within days or weeks of arriving in London. At this stage, some will become engaged or marry hoping that this will overcome their difficulty, only to find themselves enmeshed by a much greater problem and increased feelings of guilt.

Others, tiring of excessive promiscuity, try to establish a more permanent relationship but find this involves other difficulties arising from jealousy, possessiveness, and the jarring of the personality or behaviour of the less stable member of the partnership. A certain number of homosexuals do come to terms with their problems to a greater or lesser degree at this stage and are able to live adjusted useful lives on their own or with a partner. Even so, it seems that there is a general feeling of uncertainty, so that after a quarrel or other disturbance one or the other will have a casual affair resulting in venereal infection.

Over 35 years.-The fear of growing old is constantly in the mind of even the young homosexual, and the fear of increasing loneliness and rejection because he is no longer young and attractive haunts the older man. It seems that after the age of 35 more men tend to have casual affairs, haunting public lavatories or places where young male prostitutes are readily available. Others find that some young homosexuals are more attracted to older men and, being flattered by this, fall an easy prey to this type of casual relationship. Many say that sheer loneliness and boredom drive them out to find someone to talk to and that this frequently leads to a sexual relationship.

Differences in Background and Causative Factors.It seems to be increasingly apparent that in many homosexuals the causative factors are rooted in the emotional development of childhood. Many were aware before puberty, often at 7 to 8 years, that they were "different" from the other boys and felt isolated because of this. Parental influences also seem to have considerable bearing on their problem: with some it is a possessive, ambitious mother, with others, an ineffectual, drunken, or bullying father where the son may have to act as a buffer between the parents; with others it is the athletic, extrovert father whose son is sensitive and introverted, so that there is no understanding between them and the son has a constant sense of failure and inadequacy. There are also some whose home background appears to have been happy and well adjusted. 
Physical and Hereditary Factors.-Some patients recently have mentioned close relatives whom they have known to be homosexuals: One man knew that his grandfather, two uncles, and a first cousin were homosexuals. Another had four brothers all of whom were homosexuals, two having committed suicide because of it, and he also knew of at least two first cousins who were homosexuals.

Married Homosexuals. - The need to live a double sexual life and the constant fear of exposing wife and family to venereal disease or to public scandal is a very heavy burden to carry. Sometimes, in the first year or so of marriage, homosexuals feel that they are succeeding, but when difficulties arise, such as quarrels or the wife's pregnancy, they find their homosexual drives are not only still with them, but even stronger than before. The fear of blackmail or police action is a constant worry to such men.

\section{Recurrent Factors}

(1) Intense Loneliness.-Homosexuals often complain of isolation within themselves, which they feel even when participating in "gay" parties where only Christian names are used and the participants remain as anonymous as possible.

(2) Living a "Double Life".-They worry lest family or parents find out about their homosexual activities. Often one feels that parents may suspect the truth but prefer not to be told. There is always the fear of police action, or blackmail which may expose the homosexual to his business colleagues or friends, and lose him his job. Material security and comfort seem to be of particular importance to many homosexuals.

(3) They tend to associate with an almost exclusively homosexual group of friends.

(4) They need to excel at work, which is one way of obtaining the satisfaction of being above the average in at least this aspect of life.

Function of the Medical Social Worker.-The first essential is to provide an atmosphere of understanding and concern for the homosexual, in which he feels free to discuss his difficulties without fear of moral judgement. Few have ever previously discussed their problem except with homosexuals, and the fact that they can talk freely in this professional relationship often provides a bridge by which they can venture away from their associates and discover that there are people who are willing to try to understand their problems and who can respect them as individuals with strengths as well as weaknesses.
It is necessary to help them to understand their problems so that they can learn to live with them. This is done by helping them to build up their selfrespect, by widening their choice of friends to include heterosexual people, and by helping them to find some creative occupation or hobby which may give them a sense of purpose in their periods of loneliness and boredom.

Help can be given at times of crisis, for example during periods of depression or during daily treatment for syphilis. The patient is told of the availability of psychiatric help and what that involves, although unless he has the necessary desire to be helped he is unlikely to complete the long and time-consuming course of treatment.

Quite a number of homosexuals have been closely linked with religious groups at an earlier stage but have cut themselves off because of their feelings of guilt. There are certain clergy, to whom one may introduce them, who will deal with their problems with compassion and understanding.

\section{Female Homosexuals}

Girls and young women who are overtly homosexual are rarely seen in Special Clinics. On a few occasions in the past, art or drama students have mentioned rather brief lesbian affairs with older women, but recently I have encountered two teenage girls and one young adult who have discussed this problem with me more fully. Each demonstrated different aspects of this way of life. Although the material is very limited, certain factors which have emerged may be of interest.

It appears that there is less promiscuity among lesbians than among male homosexuals, but many prostitutes and most girls who work in 'clip joints' are lesbians. There are married women, often in the higher income groups, who take rooms in Mayfair and the West End of London to which girls are invited by private arrangement, for substantial fees. These meetings may be arranged through the Cypriot or Maltese owners of mixed homosexual clubs. Because many of these young girls are not working and often take drugs this is a great temptation. One girl who was tempted by the $£ 20$ minimum fee offered to her refused when she learned she would be taken to the meeting place in a car by two Greek men, as she said "knowing them they would almost certainly rape me first".

There are a number of lesbian clubs in the West End and Chelsea areas, and apparently they have a kind of hierarchy. There is one particular club where the members must be society or professional women or be introduced by an already established member. Others cater for particular groups of girls and there 
are a few clubs and public houses which cater for homosexuals of both sexes. As with male homosexuals only Christian names or nicknames are used in the clubs. Many of the lesbians who frequent the West End and the various clubs take drugs, usually hashish and "purple hearts". The fear of being caught in possession of drugs haunts most of them and they commonly deposit packages containing the drugs in dustbins and other hiding places on the fringe of the West End as they go in, and collect them again on their way home.

The social backgrounds of these girls had several interesting common factors. All had been rather petted by their fathers when they were younger and then rejected during adolescence because they had become "difficult". Two described themselves as pathological liars and made a regular practice of petty stealing from shops. Both these girls have been to expensive public boarding schools for several years, and the third attended a grammar school.

One girl aged 20 had just realized she was a lesbian and said she had "at last found sexual satisfaction". She had previously admitted that, although she had been very promiscuous, she had had sexual intercourse only with men she disliked or despised. The other two, although recognizing their intense dislike of sexual relationships with men, longed to be able to make normal heterosexual relationships and to settle down to married life. All three had been introduced to lesbian relationships by older women -one by a girl of 18 when she was aged 12 at school, another by an older married society woman whose husband was aware of what was happening but ignored it, and the third by a flatmate, a medical student several years older than herself.

Even the limited information from these girls makes it clear that lesbians have as many, if not more, conflicts and problems than male homosexuals. 